\title{
Antimicrobial Susceptibility and Public Health Importance of Salmonella Isolated from Raw Chicken Egg in MizanTeferi Town, South West Ethiopia
}

\author{
Shimelis Mengistu Hailu ( $\nabla$ shimemenge2@gmail.com ) \\ Haramaya University, College of Veterinary Medicine \\ Melkamu Melese \\ Masha livestock and fishery office, Ethiopia \\ Berhanu Sibhat \\ Haramaya University, College of Veterinary Medicine

\section{Pawlos Wasihun} \\ Haramaya University, College of Veterinary Medicine

\section{Selamawit Fentahun} \\ Wollo University
}

\section{Research Article}

Keywords: Salmonella species, Antimicrobial Resistance, salmonellosis, vaccination

Posted Date: February 8th, 2021

DOI: https://doi.org/10.21203/rs.3.rs-155972/v1

License: () (1) This work is licensed under a Creative Commons Attribution 4.0 International License. Read Full License 


\section{Abstract}

Background: Salmonella is a leading cause of food-borne illness in many countries with eggs and poultry being important vehicles of transmission and display high natural susceptibility levels to the most commonly used antibacterial agents. The study was carried out to estimate the prevalence and antibiotic susceptibility of Salmonella spp. isolated from fresh raw chicken eggs collected from MizanTeferi town, South Eastern, Ethiopia.

Results: From the total of 366 eggs examined for Salmonella spp, 27(7.4\%) were positive, of which $23(6.3 \%)$ and 4 (1.1\%) were isolated from egg shell and egg content, respectively. The prevalence of Salmonella spp. in egg and egg content from open market $(7.6 \%),(1.6 \%)$ was significantly higher than the prevalence of Salmonella spp. in poultry farm $(7.1 \%),(0.5 \%)(P<0.05)$ respectively. Ciprofloxacin ( $85.2 \%)$ showed maximum susceptibility, followed by tetracycline $(77.7 \%)$ and gentamycin $(66.6 \%)$. Clindamycin was the most resisted $(51.8 \%)$, followed by ampicillin (44.4\%), amoxicillin (40.7\%) and erythromycin (33.3\%). Most of the isolates are resistant to multiple antimicrobial agents tested. Questionnaire survey was also carried out on 200 consumers and egg sellers (100 from each group). Their preferred form of egg consumption revealed that $67.5 \%$ egg consumers preferred only cooked eggs while $32.5 \%$ egg consumers showed preference for raw eggs. Twenty nine (44.6\%) respondents who practiced eating raw eggs faced problems like nausea and vomiting, abdominal discomfort and diarrhea, while thirty six (55.4\%) faced no problems following raw eggs consumption.

Conclusion: To minimize the potential contamination of the egg by the pathogen, they should be properly handled, transported, cooked and kept appropriately. In general, public health measures such as improved food hygiene and health education are of paramount importance.

\section{Background}

Poultry, egg and egg products are among the most nutritious foods on earth and they share an important part of the human diet. However, they are perishable just like meat, fish and other food items, and consumption of improperly handled poultry and egg products are closely associated with negative health impacts causing a food-borne illness, such as salmonellosis [1]. Poultry gets infected by Salmonella serovars among which $S$. Typhimurium, $S$. Enteritidis and $S$. Heidelberg are known to infect many hosts. But, Salmonella Enteritidis, Salmonella Kentucky, Salmonella Heidelberg are serovars most commonly diagnosed associated with infection in chickens [2].

Salmonellosis is an important zoonotic disease caused by the genus Salmonella which constitutes a major public health burden and represents a significant cost in many countries [3]. Poultry eggs, meat and their products are the commonest vehicles of Salmonella spp. to humans [4]. Every year millions of human cases of salmonellosis are reported worldwide and which results in thousands of deaths [5].

Salmonella can be spread from infected hens to the yolk or albumen of developing eggs in different regions of the reproductive tract [6]. Although Salmonella can survive or slowly multiply in egg albumen [7, 8]; rapid multiplication occurs in egg yolk [9]. Because high levels of contaminants have seldom been reported in freshly laid eggs, initial Salmonella deposition inside nutrient-rich yolks appears to be relatively uncommon [10]. Moreover, freshly laid eggs are typically reported to contain no more than a few hundred Salmonella cells [11],

Antimicrobial resistance is a major and increasing global healthcare problem [12]. Considerable debate surrounds the relationship between antimicrobial use in animals and the resistance problem in people [13]. The presence of resistant organisms in the poultry and poultry products for consumption is a safety concern to the population and therapeutic concern for the physicians which might pose prolonged treatment in cases of outbreaks, delayed recovery or treatment failure [14].

Salmonellosis is endemic in the country and there is a desire to strengthen the monitoring and surveillance of salmonellosis using suitable diagnostic tools so as to prevent and control its occurrence. Based on the ubiquitous nature of Salmonella spp. and previous studies made in Ethiopia, it was hypothesized that eggs sold in local markets and poultry farm may serve as a source of Salmonella species particularly among those raw egg consumers and considerable proportion of them might have developed resistance to antimicrobials that are commonly used both in the veterinary and public health sectors. Therefore, the purpose of the present study was to isolate and determine the proportion of Salmonella spp. among two groups and antimicrobial susceptibility of Salmonella spp. 
isolates from chicken eggs collected from the MizanTeferi local markets and poultry farm. It also aims at assessing the egg handling and consumption habits of farmers and egg consumers in the study area.

\section{Methods}

\section{Description of Study area}

The study was conducted in MizanTeferi town which is located in the Bench Maji Zone (BMZ), south western part of Ethiopia as indicated in Fig. 1. Agro ecologically BMZ consists of 52\% lowland (500-1500 metres above sea level), 43\% intermediate highland (1500-2300 metres above sea level) and $5 \%$ highland ( $>2300$ metres above sea level). The mean annual temperature and rainfall varies from $15.1^{\circ} \mathrm{C}-27.5^{\circ} \mathrm{C}$ and $400-2000 \mathrm{~mm}$ respectively [15].

\section{Figure 1: Map of study area}

\section{Study Design And Sampling Strategies}

Comparative cross-sectional study (between poultry farm and local markets) was conducted on raw chicken eggs destined for human consumption from MizanTeferi poultry farms and local markets (directly from the farmers in Mizan) was conducted from December, 2017 to April, 2018. The sample size required for this study was determined based on the prevalence of Salmonella spp. done by [16] on chicken table eggs at Kombolcha, Northern Ethiopia. The prevalence was $10.5 \%$ from poultry farm and $3 \%$ from local markets [16]. The estimate was desired to be with $5 \%$ sampling error and $95 \%$ confidence intervals. The sample size was calculated using the following formula for each sampling sites [17].

$$
n=\frac{\left(1.96^{2} \sqrt{2 P 1(1-P 1)}-Z \beta \sqrt{P 1(1-P 1)+P 2(1-P 2)}\right)^{2}}{(P 2-P 1)^{2}}
$$

Where $\mathrm{P} 1$ and $\mathrm{P} 2$ are the expected proportions in each group, $\mathrm{Z}_{\beta}$ is power

$\mathrm{n}=$ No. of sample size.

$P_{1}=10.5 \%$ (from farm); $P_{2}=3 \%$ (from local market) [16].

$Z_{\beta-}=\operatorname{power}(80 \%)=0.8$

Accordingly, a total of 366 eggs; 183 eggs from semi- intensive poultry farms in Mizan and 183 eggs from Mizan open market directly from the farmers was collected. Thirty eggs from market (one egg from one egg seller) and poultry farm (15 from each group) was collected once per week using systematic random sampling technique. Eggs were collected individually in separate sterile bags, placed on ice in an ice box and transported to the Mizan Regional Veterinary Laboratory. Samples were processed within four hours upon arrival. In cases where there were delays, samples were stored in a refrigerator at $4^{\circ} \mathrm{C}$.

\section{Sample Processing}

The sterile plastic bags containing selected eggs were open with scissors and the samples processed immediately. Swabs were used to sample the shell surface of the intact eggs. Sterile cotton swabs dipped into sterile buffered peptone water (Oxoid) (CM1049) was used to swab the entire surface area of the egg shell. The same eggs from which shell sample collected will be used for interior (egg contents) sampling. The egg's surface was sterilized using $70 \%$ ethanol followed by flaming and then cracked open with a sterile scalpel blade. The isolation was conducted utilizing the conventional methods for the detection of Salmonella spp. following the standard guidelines from ISO 6579 [18].

\section{Antimicrobial Susceptibility Testing}

The antimicrobial susceptibility testing was done by the agar disk diffusion method as described by the Clinical and Laboratory Standards Institute [19]. The pure Salmonella spp. isolates confirmed by the biochemical testing procedure as described in ISO 6579 : 
2002 was tested for antimicrobial susceptibility. The antibiotics to be used were selected among the currently available and commonly used chemotherapeutic agents for treatment of Salmonella infection in human and animals such as amoxicillin $25 \mu \mathrm{g}$ (AMX), ampicillin $10 \mu \mathrm{g}(\mathrm{AM})$, chloramphenicol $30 \mu \mathrm{g}(\mathrm{C})$, ciprofloxacin $5 \mu \mathrm{g}(\mathrm{CIP})$, clindamycin $2 \mu \mathrm{g}(\mathrm{CM})$, erythromycin $15 \mu \mathrm{g}(\mathrm{E})$, gentamycin $10 \mu \mathrm{g}$, kanamycin $30 \mu \mathrm{g}(\mathrm{K})$, spectinomycin $100 \mu \mathrm{g}(\mathrm{SPT})$, tetracycline $10 \mu \mathrm{g}(\mathrm{TE})$, penicillin10 $\mu \mathrm{g}(\mathrm{P})$ and clindamycin 5 $\mu \mathrm{g}(\mathrm{CM})$.

\section{Questionnaire Survey}

Structured questionnaire was administered to farmers/ egg sellers/ and consumers to identify conditions of handling practice (storage), transportation, preparation, utilization patterns of chicken eggs, assessment about habits of consuming raw egg and related hazards in the study area by interviewing type. Sample size determination for questioner was based on [20].

$\mathrm{N}=\underline{0.25}$

$S E^{2}$

where, N-sample size SE-standard error=5\%

$=0.25 / 0.05^{2}=100$

Accordingly, a total of 200 questionnaires; 100 to consumer and 100 to farmers or egg sellers was interviewed. Mizan town has five kebele which are subdivided in to sub kebeles (ketenas). A total 25 ketenas were found in the town and all ketenas were included. 4 (four) chicken egg sellers and 4 (four) consumers were selected from each ketenas. Each ketena has a responsible health extension worker. Random sampling of household was done by using lists of households visited by health extension workers. Once households were selected head of each household responsible for food preparation and purchaser were interviewed using structured questioners. Amharic language was used in the conditions where the language is spoken, whereas, in the areas where Amharic is not spoken interpreters were used.

\section{Data Management and Analysis}

Data management, entry and analysis were employed using Microsoft Office Excel 2007. Descriptive statistics such as percentage and proportion were used to describe samples detected positive to Salmonella spp. isolation from the total sample analysed by sources of samples and sample type. The Pearson's chi-square $\left(\chi^{2}\right)$ test was used to determine the difference in levels between study groups and the association between the prevalence of Salmonella spp. and associated factors (source and type of egg sample). Pvalue of less than 0.05 was considered to determine statistically significant differences. All statistical analysis was performed using STATA software package (version 12.1).

\section{Results}

\section{Prevalence of Salmonella species}

A total prevalence of $7.4 \%$ Salmonella spp. infected eggs was found both in egg contents and egg shell of 366 samples. From this, $6.3 \%$ and $1.1 \%$ were from egg shell and from egg contents respectively. Moreover, the prevalence of Salmonella spp. in the poultry farm was $7.1 \%$, while $7.6 \%$ was found in the market (Table 1 ).

The total prevalence of Salmonella spp. varied among the sampling sites. The prevalence of Salmonella spp. in egg shell of open market and the prevalence of Salmonella spp. in egg shell of poultry farm were not significantly different $(p>0.05)$. The prevalence of Salmonella spp. in egg contents of the open market was significantly higher than the prevalence of Salmonella spp. in egg contents of poultry farm $(0.5 \%)(p<0.05)$. The difference in prevalence observed between farm egg shell and market egg shell was not statistically significant $(p>0.05)$ as shown in Table 2.

The overall prevalence of Salmonella spp. in egg shell was statistically significantly different $(p<0.05)$ from prevalence in egg contents (Table 3). Egg shells are 6.1 (OR=6.1,95\% confidence interval 2.1-17.7) times more likely to be contaminated with Salmonella species compared to egg contents. 


\section{Farmers/egg sellers/ and Consumers Chicken Egg Use and Handling (Storage) Practice}

A total of 200 questionnaires (100 to consumer and 100 to farmers or egg sellers) were interviewed. Mizan town has five kebele which are subdivided in to sub kebeles (ketenas). Ketenas were randomly selected and households were also being randomly selected in collaboration with the ketenas health extension workers. The interviewers were subjected to enquire for the source of egg that they used to consumption. It was noted that $26 \%$ of consumers preferred to purchase from market, $51.5 \%$ were preferred to consume from homemade and $22.5 \%$ from both market and homemade. Questionnaire were also forwarded to know their preference on eating raw eggs that $32.5 \%$ egg consumers showed their preference for raw egg eating, while $67.5 \%$ dislike eating raw eggs. This is might be due to their feeding habit. The reasons given by the respondents eating raw eggs were due to the nutritious purpose and egg for the purpose of medicine $29.3 \%$ and $70.7 \%$, respectively and this could have some negative effects on health. Twenty nine (44.6\%) respondents that practiced eating raw eggs were faced a problem like nausea and vomiting, abdominal discomfort and diarrhea, while thirty six (55.4\%) were not facing the problem after eating raw eggs. This problems were may be arises from contamination of egg by the pathogen in the study area. The respondents' family consuming raw egg habit were asked and shows $44.5 \%$ have consuming raw egg for medicinal and nutritious purposes. To show their preference on type of dish they used to prepare from eggs, $42.5 \%$ preferred boiling with shell, $52 \%$ liked scrambled egg and $5.5 \%$ of the consumers liked baked eggs. The habit of washing eggs before subjecting for consumption showed that $77.5 \%$ were did not have habit of washing eggs and the rest $22.5 \%$ had a habit of washing eggs. The types of materials in which the eggs was stored before preparation showed that $65.8 \%$ of the respondent used open containers such as carton and box, while $28.3 \%$ and $5.9 \%$ were used together with crops and refrigerators respectively. The majority of the respondents $(90 \%)$ were used this storage practice to protect from breakage and the rest $10 \%$ were to prevent egg from spoilage. The survey on storage of egg before preparation showed that $72.2 \%$ stored $1-7$ days, $24.4 \%$ stored $7-15$ days and only $3.2 \%$ stored $15-30$ days. The egg consumers in MizanTeferi town during survey were also asked to what they do with cracked eggs and show that $22.5 \%$ were consuming and the rest respondents $77.5 \%$ were rejected when the egg cracked. Out of 200 respondents, only $27.5 \%$ was knowing about disease could be transmitted by consuming raw egg and the rest $72.5 \%$ were unknown (Table 4 ).

\section{Antimicrobial Resistance Testing}

Levels of antimicrobial resistance testing: All the 27 isolates of Salmonella spp. were tested for antimicrobial susceptibility testing on twelve different antimicrobials. Of these Ciprofloxacin (85.2) showed maximum susceptibility and followed by Tetracycline (77.7) and Gentamycin (66.6\%). Clindamycin was the most resisted (51.8\%), followed by Ampicillin (44.4\%), Amoxicillin (40.7\%) and Erythromycin (33.3\%). While Penicillin (33.3\%) and Spectinomycin (33.3\%) were intermediate resistant. In general, in this study antimicrobial susceptibility test revealed that Ciprofloxacin, Tetracycline and Gentamycin were the drugs indicated more active against Salmonella spp. isolated from egg samples, while Clindamycin, ampicillin and amoxicillin were less effective against Salmonella spp. isolates (Table 5).

\section{Resistance pattern of Salmonella species against 12 antimicrobial agents}

All of the isolates were resistant to at least three antimicrobial agents tested, most commonly for clindamycin, amoxicillin, ampicillin, and streptomycin (Table 6).

\section{Discussions}

In the current study out of the total 366 chicken eggs examined, $6.3 \%$ and $1.1 \%$ were positive for Salmonella spp. isolated from egg shells and egg contents, respectively (Tables $1 \& 2$ ). The results showed that Salmonella spp. contaminate egg shell was significantly higher $(6.3 \%)$ than that of egg contents $(1.09 \%)(\mathrm{P}<0.05)$.

The current study is higher prevalence of Iran studied by [21] 1.33\% in egg shell and $0 \%$ in egg contents [21], $5.3 \%$ and $0 \%$ in shell and contents respectively in Haramaya poultry farm recorded by [22] and $2.4 \%$ in shell and $0.5 \%$ in contents also in Haramaya poultry farm recorded by [23], and in South India [24], 6.1\% and 1.8\% reported in egg shells and egg contents of retail eggs, respectively. This variation is due to higher environmental contamination and loss of awareness about proper handling and storage of egg. But the current study prevalence was lower than the prevalence of $40 \%$ and $8.33 \%$ of Salmonella spp. were reported from egg shells and egg contents respectively by [25], 11.5\% in eggs from Kombolcha [16], 7.7\% in egg shell and 5.6\% in contents from Alage done by [26], 
15.38 in shell and 8.33 in contents from Mekelle done by [27] and 4.69\% in eggs from Addis Ababa [28] in the current study. Contamination of egg occurs though different factors such as contact with fecal material, insects, and feed, transportation, storage and during handling. So, variation of the different factors leads to variation in the prevalence of Salmonella spp. in eggs.

If the hygienic standard in handling, transportation and storage improves, the Salmonella spp. prevalence may lower down. This is evident from several reports of salmonellosis in eggs from developed countries where it ranges from zero to $7 \%$ in the United Kingdom [29], 0.62\% in US [30], 2.4\% in Denmark [31] and 0.4\% in Republic of Ireland [32].

Based on the source of egg collected, the prevalence of Salmonella spp. was $13(7.1 \%)$ and $14(7.6 \%)$ in egg shells and contents of poultry farm and open markets respectively. The results showed that there was no significant difference in prevalence of poultry farm and open markets $(p>0.05)$. Contrary to this finding, the study conducted in Kombolcha showed that prevalence of Salmonella spp. in contents of egg from poultry farm (10.5\%) was significantly higher than that of open market reported by [16].

Salmonella is harmful pathogen that enters the food chain supply at any points in the food production and affects the quality of eggs and the consumer's health. Salmonella is horizontally transmitted usually from fecal contamination of egg shell and egg contents by migration through the egg shell and membranes. This route of transmission is facilitated by moist egg shells, storage at ambient temperature and shell damage by Salmonella spp. This fact suggests that good animal health practice in poultry farms and food safety intervention should be established to prevent contamination of chicken eggs [1]. The food handlers directly handle raw shell eggs and broken shells may came in contact with the egg content during food preparation and processing, which could allow the pathogen to reach the egg contents and increase the prevalence.

In current study ciprofloxacin (85.2\%) showed maximum susceptibility and followed by Tetracycline (77.7\%) and gentamycin (66.6\%). Clindamycin was the most resisted (51.8\%), followed by ampicillin (44.4\%), amoxicillin (40.7\%) and erythromycin (33.3\%). While penicillin (33.3\%) and spectinomycin (33.3\%) were intermediate resistant. In this study, most of the Salmonella spp. isolates are resistant to the different antimicrobial agents tested, especially for clindamycin, amoxicillin, ampicillin, and streptomycin. The high resistance pattern of Salmonella spp. isolates against the commonly used antimicrobials is probably due to the irrational use of these antibiotics in veterinary medicine practices which creates problems in the treatment of salmonellosis [33]. In a study carried out in Eastern Ethiopia by [33], the susceptibility of the Salmonella spp. isolates were $0.0 \%, 0.0 \%, 14.2 \%, 28.6 \%$, and $92.8 \%$ for ampicillin, amoxicillin, tetracycline, chloramphenicol, and gentamicin, respectively.

In [34] study, S. newport was showed the highest level of streptomycin resistance (66.7\%). S. heidelberg and S. haifa serovars were resistant to streptomycin. The ampicillin, streptomycin and tetracycline antibiotics were resistant for the two isolates of $S$. haifa.

According to [35] study, 98 isolates of Salmonella serovars was recovered from food in Addis Ababa, Ethiopia and assessed their antimicrobial resistance. The results showed that 32 Salmonella spp. isolates were resistant to one or more of the 24 tested antimicrobials. Streptomycin (75\%), ampicillin (59.4\%), tetracycline (46.9\%) and spectinomycin (40.6\%) were the most common resistance antibiotics compared to the present study (Table 5). In study conducted in Haramaya area [22], all isolates of Salmonella spp. were resistant to clindamycin (100\%), followed by erythromycin (62.5\%), ampicillin (37.5\%), amoxicillin (37.5\%), and tetracycline (25\%) antibiotics. From the tested antibiotics, gentamicin (37.5\%), nitrofurantoin (50\%), trimethoprim (50\%), chloramphenicol (87.5\%), and ciprofloxacin (100\%) were susceptibility, respectively.

Improving biosecurity measures, vaccination, use of competitive exclusion products, introduction of novel immuno-potentiators, and limited use of antimicrobials are some of the approaches to prevent and control the disease in food animal industry [36]. The frequent use of antimicrobials in food animals causes in the development of antimicrobial resistance [37], through mutation and acquiring of resistance encoding genes [38].

In questioner survey the consumers were subjected to enquire for the source of egg that they used to consumption. It was noted that $26 \%$ of consumers preferred to purchase from market, $51.5 \%$ were preferred to consume from homemade and $22.5 \%$ from both market and homemade. Questionnaire were also forwarded to know customers preference on eating raw eggs, $32.5 \%$ egg consumers were prefer for eating raw egg, while $67.5 \%$ of the consumer not like to eat raw eggs. This difference might be to their feeding habit. The reasons given by the respondents eating raw eggs were due to the nutritious purpose (29.3\%) and medicine purpose (70.7\%), respectively. Eating of raw egg could have negative effects on health. From eating raw egg respondents, $29(44.6 \%)$ them were faced a problem like nausea and vomiting, abdominal discomfort and diarrhoea, while thirty six (55.4\%) were not facing problems. This problems were may be arises from contamination of egg by the pathogen in the study area.

Page 6/12 
The types of materials where the eggs was stored before preparation showed that $65.5 \%$ of the respondent used open containers such as carton and box, while $28.2 \%$ and $5.9 \%$ were used together with crops and refrigerators respectively. The majority of the respondents $(90 \%)$ were used this storage practice to protect from breakage and the rest $10 \%$ were to prevent egg from spoilage. The survey on storage of egg before preparation showed that $72.2 \%$ stored between $1-7$ days, $24.4 \%$ stored between $7-15$ days and only $3.2 \%$ stored between 15- 30 days (Table 3).

\section{Conclusion}

In conclusion, in the present study respective of $7.1 \%$ and $7.6 \%$ prevalence of Salmonella spp. from farm and market in Mizan Teferi suggest that egg products might be the source of human salmonellosis. Study on antimicrobial resistance results point to poultry as a potential reservoir of multi resistant Salmonella isolates, which are a serious public health concern now a days. Antibiotics should be used following assessment of antibiogram profiles and unlimited access to antimicrobial agents must be avoided to prevent the spread of multi resistant isolates. On the questionnaire survey result, most of the consumers have practiced eating raw eggs for medicinal value and this has considerable negative effect on their health. However, people consume raw and cracked eggs in the area, indicating a lack of awareness of zoonosis. Therefore, the public should be made aware of risks associated with consumption of raw chicken eggs and raw eggs cracked during storage and transportation. The prevalence of Salmonella spp. in egg contents was low. However, mixing of several eggs during food preparation particularly in undercooked or raw foods could result in high risk of Salmonella food poisoning.

\section{Abbreviations}

BPW: Buffered Peptone Water; CLSI: Clinical and Laboratory Standards Institute; ESR: Environmental Science and Research Limited; FDA: Food and Drug Administration; FRI: Food Research International; MAR: Multiple Antimicrobial Resistance; MAP: Modified Atmosphere Packaging

\section{Declarations}

\section{Financial support}

This research was supported by Haramaya University Research Grant.

\section{Data Availability}

The data used to support the findings can be obtained from the corresponding author upon reasonable request.

\section{Statement of author}

The authors confirm that all methods were carried out in accordance with relevant guidelines and regulations and the study was carried out in compliance with the ARRIVE guidelines. The authors also would like to confirm the research was approved by the board of Haramaya University.

\section{Conflict of Interests}

The authors declare that there is no conflict of interests.

\section{Author contribution statements}

Authors list

A. Shimelis Mengistu Hailu, Design the work, wrote the paper, performed the analysis and interpretation of data

B. Melkamu Melese, collected the data

C. Berhanu Sibhat, collected the data

D. Pawlos Wasihun, performed the analysis and interpretation of data 
E. Selamawit Fentahun, edited the paper

\section{Acknowledgments}

The authors would like to thank staffs of the Mizan Regional Veterinary Laboratory for their supports, particularly Dr. Zewdu Dagne, Dr. Murga Soma, Dr. Tamrat Haile and Mr. Mulugeta Abera

\section{Ethical Statement}

The study was approved by the Institutional Review Boards of the Haramaya University. Informed consent was obtained from study participants.

\section{References}

1. World Health Organization. Risk assessments of Salmonella in eggs and broiler chickens. Food \& Agriculture Org.; 2002.

2. CDC, "Preliminary food network data on the incidence of infection with pathogens transmitted commonly through food in 10 states, United States. Weekly Report," 2006; 55(6): 392-395

3. Murugkar HV, Rahman H, Kumar A, Bhattacharyya D. Isolation, phage typing \& antibiogram of Salmonella from man \& animals in northeastern India. Indian Journal of Medical Research. 2005; 122(3):237.

4. Nagappa K, Tamuly S, Saxena MK, Singh SP. Isolation of Salmonella Typhimurium from poultry eggs and meat of Tarai region of Uttaranchal. 2007. Indian Journal of Biotechnology. 2007; 6: 407-409

5. Herikstad H, Motarjemi Y, Tauxe RV. Salmonella surveillance: a global survey of public health serotyping. Epidemiology \& Infection. 2002; 129(1):1-8.

6. Gast RK, Guraya R, Guard-Bouldin J, Holt PS, Moore RW. Colonization of specific regions of the reproductive tract and deposition at different locations inside eggs laid by hens infected with Salmonella Enteritidis or Salmonella Heidelberg. Avian diseases. 2007; 51(1):40-4.

7. Chen J, Thesmar HS, Kerr WL. Outgrowth of Salmonellae and the physical property of albumen and vitelline membrane as influenced by egg storage conditions. Journal of food protection. 2005; 68(12):2553-8.

8. Guan J, Grenier C, Brooks BW. In vitro study of Salmonella Enteritidis and Salmonella Typhimurium definitive type 104: survival in egg albumen and penetration through the vitelline membrane. Poultry science. 2006; 85(9):1678-81.

9. Gast RK, Holt PS. Influence of the level and location of contamination on the multiplication of Salmonella enteritidis at different storage temperatures in experimentally inoculated eggs. Poultry Science. 2000; 79(4):559-63.

10. Kang H, Loui C, Clavijo RI, Riley LW, Lu S. Survival characteristics of Salmonella enterica serovar Enteritidis in chicken egg albumen. Epidemiology \& Infection. 2006; 134(5):967-76.

11. Gast RK, Holt PS. Deposition of phage type 4 and 13a Salmonella enteritidis strains in the yolk and albumen of eggs laid by experimentally infected hens. Avian diseases. 2000:706-10.

12. WHO (World Health Organization) Enterohaemorrhagic Escherichia coli (EHEC). 2012.

http://www.who.int/mediacentre/factsheets/fs125/en/ [Accessed March].

13. Barza M, Gorbach SL. The need to improve antimicrobial use in agriculture: ecological and human health consequences. Clin. Infect. Dis. 2002; 34: S71-S144.

14. Silbergeld EK, Graham J, Price L, Liebler J, Evans S, Vailles R, Lackey L, Peterson A, Davis M, Arriola CS, Resnick C. Industrial food animal production: food safety, socioeconomic, and environmental health concerns. Epidemiology. 2008;19(6):S15-6.

15. BMZARD, “Bench Maji zone and rural development bureau,” 2014.

16. Assefa M, Teklu A, Negussie H. The prevalence and public health importance of Salmonella from chicken table eggs, Ethiopia. Am. Eurasian J. Agric. Environ. Sci. 2011; 11:512-8.

17. Fosgate GT. Practical sample size calculations for surveillance and diagnostic investigations. Journal of veterinary diagnostic investigation. 2009; 21(1):3-14.

18. International Organization for Standardization. Microbiology of Food and Animal Feeding Stuffs: Horizontal Method for the Detection of Salmonella Spp. Detection of Salmonella spp. in animal faeces and in environmental samples from the primary production stage. Amendment 1, Annex D. ISO; 2007. 
19. Clinical and Laboratory Standards Institute. CLSI. Performance Standards for Antimicrobial Disk and Dilution Susceptibility Tests for Bacteria Isolated From Animals. 2013.

20. Arsham H. “Questionnaire Design and Surveys Sampling, SySurvey: The Online Survey Tool," 2002.

21. Moosavy MH, Esmaeili S, Amiri FB, Mostafavi E, Salehi TZ. Detection of Salmonella spp in commercial eggs in Iran. Iranian journal of microbiology. 2015: 7(1):50.

22. Kemal J, Sibhat B, Menkir S, Beyene D. Prevalence, assessment, and antimicrobial resistance patterns of Salmonella from raw chicken eggs in Haramaya, Ethiopia. The Journal of Infection in Developing Countries. 2016;10(11):1230-5.

23. Tessema K, Bedu H, Ejo M, Hiko A. Prevalence and antibiotic resistance of Salmonella species isolated from chicken eggs by standard bacteriological method. J Vet Sci Technol. 2017; 8(421):2.

24. Suresh T, Hatha AA, Sreenivasan D, Sangeetha N, Lashmanaperumalsamy P. Prevalence and antimicrobial resistance of Salmonella enteritidis and other salmonellas in the eggs and egg-storing trays from retails markets of Coimbatore, South India. Food microbiology. 2006; 23(3):294-9.

25. Akhtar F, Hussain I, Khan A, Rahman SU. Prevalence and antibiogram studies of Salmonella enteritidis isolated from human and poultry sources. Pak. Vet. J. 2010; 30(1):25-8.

26. Tsegaye S, Beyene W, Tesfaye B, Tesfaye S, Feleke A. Prevalence and antimicrobial susceptibility pattern of Salmonella species from exotic chicken eggs in Alage, Ziway and Shashemene, Ethiopia. Afr J Basic Appl Sci. 2016; 8:180-4.

27. Nguse D, Kumar A, Balcha E. Prevalence of Salmonella in Eggs Collected from Local Markets and Poultry Farms in Mekelle, Ethiopia. European Journal of Biological Sciences. 2015; 7(1):41-4.

28. Bayu Z, Asrade B, Kebede N, Sisay Z, Bayu Y. Identification and characterization of Salmonella species in whole egg purchased from local markets in Addis Ababa, Ethiopia. Journal of Veterinary Medicine and Animal Health. 2013; 5(5):133-7.

29. European Food Safety Authority, "Report of the task force on zoonoses data collection on the analysis of the baseline study on the prevalence of Salmonella in holdings of laying flocks of Gallus gallus," EFSA J. 2007; 97: 1-84.

30. FSIS, "The FSIS microbiological testing program for pasteurized egg products," 1995-2009, 2010. Accessedat:http://www.fsis.usda.gov/Science/Sal_Pasteurized_Egg_Products/index.asp.Accessed: 29 March, 2011.

31. European Food Safety Authority (EFSA). Preliminary report on Analysis of the baseline study on the prevalence of Salmonella in laying hen flocks of Gallus gallus. EFSA Journal. 2006; 4(6):81r.

32. Murchie L, Whyte P, Xia B, Horrigan S, Kelly L, Madden RH. Prevalence of Salmonella in grade A whole shell eggs in the island of Ireland. Journal of food protection. 2007; 70(5):1238-40.

33. Reda AA, Seyoum B, Yimam J, Fiseha S, Jean-Michel V. Antibiotic susceptibility patterns of Salmonella and Shigella isolates in Harar, Eastern Ethiopia. Journal of Infectious Diseases and Immunity. 2011; 3(8):134-9.

34. Sibhat B, Molla Zewde B, Zerihun A, Muckle A, Cole L, Boerlin P, Wilkie E, Perets A, Mistry K, Gebreyes WA. Salmonella serovars and antimicrobial resistance profiles in beef cattle, slaughterhouse personnel and slaughterhouse environment in Ethiopia.

Zoonoses and public health. 2011; 58(2):102-9.

35. Zewdu E, Cornelius P. Antimicrobial resistance pattern of Salmonella serotypes isolated from food items and personnel in Addis Ababa, Ethiopia. Tropical Animal Health and Production. 2009; 41(2):241.

36. Zhao S, McDermott PF, White DG, Qaiyumi S, Friedman SL, Abbott JW, Glenn A, Ayers SL, Post KW, Fales WH, Wilson RB. Characterization of multidrug resistant Salmonella recovered from diseased animals. Veterinary microbiology. 2007;123(1-3):12232.

37. White DG, Zhao S, Sudler R, Ayers S, Friedman S, Chen S, McDermott PF, McDermott S, Wagner DD, Meng J. The isolation of antibiotic-resistant Salmonella from retail ground meats. New England journal of medicine. 2001; 345(16):1147-54.

38. Fluit AC. Towards more virulent and antibiotic-resistant Salmonella?. FEMS Immunology \& Medical Microbiology. 2005; $43(1): 1-1$.

39. Yildirim Y, Gonulalan Z, Pamuk S, Ertas N. Incidence and antibiotic resistance of Salmonella spp. on raw chicken carcasses. Food Research International. 2011; 44(3):725-8.

\section{Tables}

Table 1: Prevalence of Salmonella spp. by type and source of sample examined 


\begin{tabular}{lccclcl}
\hline Source of sample & No. examined & Egg shell & Egg & content & Total & Prevalence (95\% CI) \\
\hline Farm & 183 & 12 & 1 & 13 & $7.1(3.8-11)$ \\
Market & 183 & 11 & 3 & 14 & $7.6(4.0-12)$ \\
Total & 366 & 23 & 4 & 27 & $7.4(4.9-10)$ \\
\hline
\end{tabular}

Table 2: The prevalence of Salmonella spp. between farm and market on egg shell and content

\begin{tabular}{lcccc}
\hline Sample type & Farm (n=183) & Market (183) & $\mathbf{2}$ & p-value \\
\hline Egg shell & $12(6.5 \%)$ & $11(6.01 \%)$ & 0.04 & 0.842 \\
Egg content & $1(0.5 \%)$ & $3(1.6 \%)$ & 14.43 & 0.000 \\
Total & $13(7.1 \%)$ & $14(7.6 \%)$ & & \\
\hline
\end{tabular}

Table 3: The prevalence of Salmonella spp. in egg shell and egg contents

\begin{tabular}{lcccc}
\hline Source of sample & No. of positive & Prevalence (\%) & 2* & p-value \\
\hline Egg shell (366) & 23 & 6.3 & 13.88 & 0.000 \\
Egg content (366) & 4 & 1.1 & & \\
\hline
\end{tabular}

(The ${ }^{2 *}$ used is Fisher's exact.)

Table 4: Handling and consumption practice of eggs among egg sellers and consumers

\section{Question Items}

What is the source of egg used for consumption? Home made

Purchased from market

Both from market and home made

Do you consume raw egg?

Does your family consume raw egg?

If yes, for what reason do they consume?

If

Have you ever had any sickness FF raw

If yes, what was the symptom?

egg consumption?

Nausea and vomiting

Abdominal discomfort

Diarrhea

Do you know that disease could be transmitted by raw egg?

Do you wash the egg before preparation to consumption

Do you keep the egg at home?

If yes, for how many days?

In what way do you keep the egg at home?

What do you do with cracked eggs?

Which cooking method do you used?

\begin{tabular}{|c|c|c|c|c|}
\hline & 45 & 2.5 & 155 & 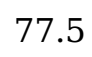 \\
\hline & 184 & 92 & 16 & 8 \\
\hline & 33 & 72.2 & 51 & 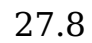 \\
\hline $7-15$ & 45 & 4.4 & 39 & 5. \\
\hline 15-30days & 6 & 3.2 & 178 & 96.8 \\
\hline onta & 121 & 65.8 & 63 & 4. \\
\hline ith & 52 & 28.3 & 132 & 71. \\
\hline ri & 11 & 5.9 & 173 & 94. \\
\hline Const & 45 & 22.5 & 155 & 77. \\
\hline Reje & 155 & 77.5 & 10 & 22. \\
\hline & 85 & 42. & 115 & 57. \\
\hline rambli & 104 & 52 & 96 & 48 \\
\hline Baking & 11 & 5.5 & 189 & 4. \\
\hline
\end{tabular}

Respondents response

yes \% No \%

$\begin{array}{llll}103 & 51.5 & 97 & 48.5\end{array}$

$\begin{array}{llll}52 & 26 & 148 & 74\end{array}$

$\begin{array}{llll}45 & 22.5 & 155 & 77.5\end{array}$

$\begin{array}{llll}65 & 32.5 & 135 & 67.5\end{array}$

$\begin{array}{llll}89 & 44.5 & 111 & 55.5\end{array}$

$\begin{array}{llll}63 & 70.7 & 26 & 29.3\end{array}$

$\begin{array}{llll}26 & 29.3 & 63 & 70.7\end{array}$

$\begin{array}{llll}29 & 44.6 & 36 & 55.4\end{array}$

$\begin{array}{llll}11 & 37.9 & 18 & 62.1\end{array}$

$\begin{array}{llll}12 & 41.3 & 17 & 58.7\end{array}$

$\begin{array}{llll}6 & 20.6 & 23 & 79.4\end{array}$

$\begin{array}{llll}55 & 27.5 & 145 & 72.5\end{array}$

$\begin{array}{llll}45 & 22.5 & 155 & 77.5\end{array}$

8


Table 5: Antimicrobial susceptibility of Salmonella spp. isolates $(\mathrm{n}=27)$

\begin{tabular}{lcccccc}
\hline Antimicrobial tested & \multicolumn{2}{c}{ Resistance isolates } & \multicolumn{2}{c}{ Intermediate isolates } & \multicolumn{2}{c}{ susceptible isolates } \\
\cline { 2 - 7 } & No. & $\%$ & No. & $\%$ & No. & $\%$ \\
Gentamycin & 4 & 14.8 & 5 & 18.5 & 18 & 66.6 \\
Chloramphenicol & 3 & 11.1 & 7 & 26 & 17 & 62.9 \\
Penicillin & 7 & 25.9 & 9 & 33.3 & 11 & 40.7 \\
Ampicillin & 12 & 44.4 & 8 & 29.6 & 7 & 25.9 \\
Erythromycin & 9 & 33.3 & 6 & 22.3 & 12 & 44.4 \\
Kanamycin & 8 & 29.6 & 7 & 25.9 & 12 & 44.4 \\
Amoxicillin & 11 & 40.7 & 5 & 18.6 & 11 & 40.7 \\
Streptomycin & 10 & 37 & - & - & 17 & 63 \\
Tetracycline & 6 & 22.3 & - & - & 21 & 77,7 \\
Ciprofloxacin & 3 & 11.1 & 1 & 3.7 & 23 & 85.2 \\
Clindamycin & 14 & 51.8 & 3 & 11.1 & 10 & 37.1 \\
Spectinomycin & 7 & 25.9 & 9 & 33.3 & 11 & 40.7 \\
\hline
\end{tabular}

Table 6: Resistance patterns exhibited by Salmonella spp. isolates against 12 antimicrobial agents.

\begin{tabular}{lccc}
\hline Salmonella spp. isolates & $\begin{array}{c}\text { No. } \\
\text { Isolates } \\
\text { with } \\
\text { same } \\
\text { pattern }\end{array}$ & Antimicrobial resistance pattern & $\begin{array}{c}\text { No. of } \\
\text { antimicrobials } \\
\text { developed } \\
\text { resistance }\end{array}$ \\
\hline M21S,M36S,M57C,M80S, M99S & 5 & CLN,AMP,AMX & 3 \\
M10S,M126S,M245S & 3 & CLN,AMP,AMX,STR,GEN & 5 \\
M29S,M209S,M47C, & 6 & CLN,AMP,AMX,STR,ERY,KAN & 6 \\
M303S,M309S,M322S & 3 & CLN,AMP,STR,PEN,TET,KAN,CIP & 7 \\
M43S, M66S, M109C & 4 & CLN,ERY,CHL,SPS,AMP,PEN,GEN,KAN & 8 \\
M328S, M346S, M227S, M317S & 6 & CLN,AMP,AMX,STR,KAN,PEN,CHL,TET,CIP,ERY & 10 \\
M89S,M338C,M342S,M355S,M360S, & & \\
M363S & &
\end{tabular}

CLN: clindamycin; ERY: erythromycin; KAN: kanamycin; TET: tetracycline; AMP: ampicillin; AMX: amoxicillin; GEN: gentamycin; SPC: spectinomycin; PEN: penicillin; STR: streptomycin; CIP: ciprofloxacin; CHL: chloramphenicol.

\section{Figures}




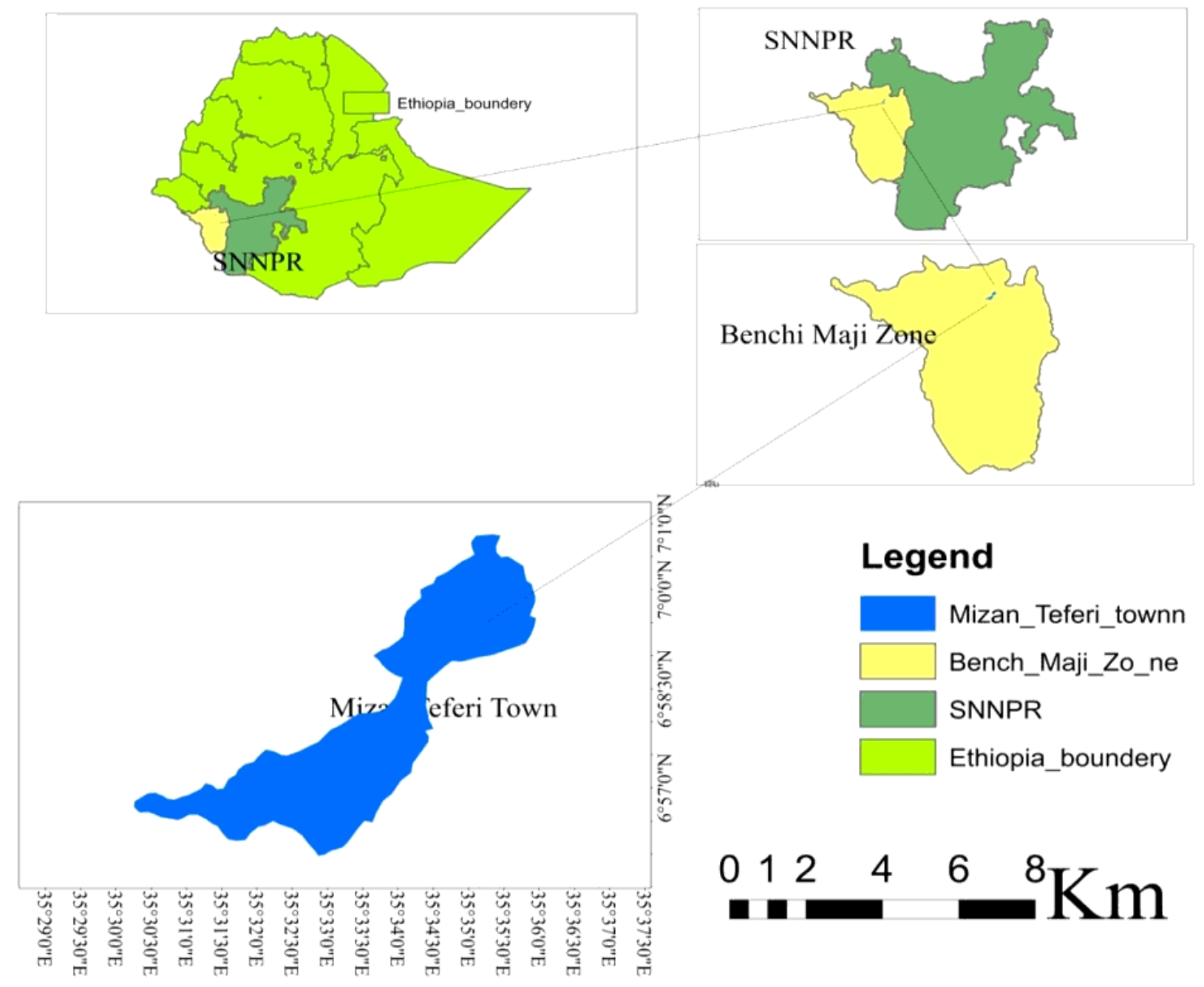

Figure 1

Map of study area

\section{Supplementary Files}

This is a list of supplementary files associated with this preprint. Click to download.

- Questionnaire.docx 